\title{
Advances and Drawbacks of the Adaptation to Serum-Free Culture of CHO-K1 Cells for Monoclonal Antibody Production
}

\author{
Maria Elisa Rodrigues • Ana Rita Costa • \\ Mariana Henriques • Philip Cunnah • \\ David W. Melton • Joana Azeredo • Rosário Oliveira
}

Received: 7 September 2012 / Accepted: 26 December 2012 /

Published online: 11 January 2013

(C) Springer Science+Business Media New York 2013

\begin{abstract}
Currently, mammalian cell technology has become the focus of biopharmaceutical production, with strict regulatory scrutiny of the techniques employed. Major concerns about the presence of animal-derived components in the culture media led to the development of serum-free (SF) culture processes. However, cell adaptation to SF conditions is still a major challenge and limiting step of process development. Thus, this study aims to assess the impact of SF adaptation on monoclonal antibody (mAb) production, identify the most critical steps of cell adaptation to the SF EX-CELL medium, and create basic process guidelines. The success of SF adaptation was dependent on critical steps that included accentuated cell sensitivity to common culture procedures (centrifugation, trypsinization), initial cell concentration, time given at each step of serum reduction, and, most importantly, medium supplements used to support adaptation. Indeed, only one of the five supplement combinations assessed (rhinsulin, ammonium metavanadate, nickel chloride, and stannous chloride) succeeded for the Chinese hamster ovary-K1 cell line used. This work also revealed that the chemically defined EX-CELL medium benefits mAb production in comparison with the general purpose Dulbecco's Modified Eagle's Medium, but the complete removal of serum attenuates these positive effects.
\end{abstract}

Keywords Chinese hamster ovary cells $\cdot$ Monoclonal antibody $\cdot$ Production $\cdot$ Serum-free medium $\cdot$ Trace elements $\cdot$ Cell adaptation

\footnotetext{
M. E. Rodrigues $\cdot$ A. R. Costa $\cdot$ M. Henriques $(\bowtie) \cdot J$. Azeredo $\cdot$ R. Oliveira IBB - Institute for Biotechnology and Bioengineering, Centre of Biological Engineering, University of Minho, 4710-057 Braga, Portugal

e-mail: mcrh@deb.uminho.pt

P. Cunnah

Biotecnol, Lagoas Park, Edifício 7, 2741-901 Porto Salvo, Portugal

D. W. Melton

Edinburgh Cancer Research Centre, University of Edinburgh, Edinburgh EH4 2XU, Scotland
} 


\section{Introduction}

Mammalian cells are of great interest for biopharmaceutical applications, namely in the industrial production of recombinant therapeutic glycoproteins, due to their ability to perform human-like post-translational modifications resulting in a fully active product [18, $24,30,32]$. One of the most important cell lines used in the production of these recombinant proteins, such as monoclonal antibodies (mAbs), is the Chinese hamster ovary (CHO) cell line, which has attractive features for large-scale production such as the support of a stable and high-level product expression over time, scalability, and the ability to provide proper post-translational processing [22].

A major objective of the biopharmaceutical industry is to decrease costs while increasing the production yield. Furthermore, a robust culture system with predictable and reliable highdensity cell growth and/or specific cell productivity is greatly desired [13]. However, with the increasing number of mAbs being used as therapeutic agents, methods employed for their production are coming under strict regulatory scrutiny, which may interfere with the optimal production process [33]. One of the areas of main concern for regulatory entities is the presence of animal-derived components in the media employed [22]. Indeed, the original adherent growth conditions of most mammalian cells, such as $\mathrm{CHO}$, require the use of serumcontaining medium $[2,17,19,23]$. However, the use of serum in the culture media has many drawbacks. From a practical point of view, serum is an ill-defined mixture of components which raises ethical and animal welfare problems regarding its harvest and collection, and there are constraints in terms of global supply versus demand [2, 8, 18, 24, 33]. Concerning cell biological perspectives, the disadvantages of serum supplementation are manifold: (1) serum batches display quantitative and qualitative variations in their composition and thus introduce a serious lot-to-lot variability; (2) serum may contain many different proteins, which can hinder product purification; (3) serum can also interfere with the effect of hormones or growth factors when studying their interaction with cells; (4) serum can be a potential source of microbial contaminants, such as fungi, bacteria, viruses, mycoplasma, and prions, posing a risk of transmission of diseases to the end product used by humans; and (5) serum is associated with high-costs $[2,8,18,19,23,24,33]$. Considering all these reasons, it is essential to develop a simple cell adaptation process for the culture of cells in serum-free, animal component-free, or protein-free medium conditions [18, 22, 26, 31].

Recently, there have been many efforts to develop serum-free media for the production of therapeutic proteins in mammalian cell culture $[3,25,27]$. This has led to the development of several commercial serum-free media specific for $\mathrm{CHO}$ cell culture [19]. However, serumfree medium development is a commercially competitive field, and the composition of most of these media is patented, making further improvements difficult [19].

Mammalian cell growth can be adapted to serum-free media through progressive reductions of serum concentrations $[5,26]$. This gradual reduction over time increases the probability of successful adaptation to low-serum or serum-free media [23] by allowing the self-adjustment of the cells to the environment, with the time required depending on the cell line and the composition of the media [10]. To achieve the final step of adaptation, it is common to add supplements that support cell growth, such as commercial serum substitutes, defined proteins, or small molecules such as amino acids or trace elements. Among these, the use of small molecules is the most difficult to achieve, but it may ultimately prove to be the most useful [5].

During the process of adaptation, it is critical to monitor the cell growth rate since its increase is the first sign of a successful adaptation [18, 23]. Furthermore, the measurement of protein production is also critical $[5,18,21]$ and, depending on the product or cell type, gain or loss of productivity can be observed [21]. 
The transition to serum-free conditions is not straightforward. However, once cells have been adapted, researchers can benefit from improved control over culture conditions, improved reproducibility between cultures, consistency of media that avoids the need to screen batches, potential ease in scale-up operation, simplicity in downstream processing, reduced risk of virus contamination, and reduced costs [3, 5, 8, 25, 27, 29].

This study aims to evaluate a methodology for the adaptation of CHO-K1 cells, producing the mAb CAB051, to grow in the chemically defined serum-free medium EX-CELL CHO $\mathrm{DHFR}^{-}$, and assess its impact on mAb production, as well as to identify the most critical steps of the process. To accomplish this, a methodology of gradual adaptation was implemented, supported by medium supplementation with different combinations of trace elements.

\section{Materials and Methods}

\section{Cell Lines and Cell Culture}

Three cell types were used in this study: cell line A - the main CHO-K1 cell line transfected with the CAB051 mAb (Biotecnol SA, Lisbon, Portugal) by OSCAR ${ }^{\mathrm{TM}}$ technology (University of Edinburgh, Scotland); and two additional cell lines that were used to assess the impact of transfection on the process of adaptation, namely cell line B-the original nonproducing $\mathrm{CHO}-\mathrm{K} 1$ cell line (ATCC), and cell line $\mathrm{C}-\mathrm{a} \mathrm{CHO}-\mathrm{K} 1$ cell line also producing the CAB051 mAb but transfected by a common technology (kindly provided by Biotecnol SA).

The different cells were grown in Dulbecco's Modified Eagle's Medium (DMEM, SigmaAldrich, Dorset, UK) supplemented with $10 \%$ of fetal bovine serum (FBS, Sigma-Aldrich), and with $1 \times$ hypoxanthine-aminopterin-thymidine (HAT, Sigma-Aldrich) only for cell line A at $37{ }^{\circ} \mathrm{C}$ and in a humidified atmosphere at $5 \% \mathrm{CO}_{2}$.

\section{Adaptation Methodology}

\section{Direct Adaptation to Serum-Free Medium}

Cells growing in serum-containing medium were inoculated, in $25-\mathrm{cm}^{2}$ flasks, at a viable cell density of $2 \times 10^{5}$ cells per milliliter in a $1: 1$ mixture of serum-containing medium (DMEM supplemented with FBS) and serum-free medium (EX-CELL CHO DHFR ${ }^{-}$medium, Sigma-Aldrich). After reaching a density of $1 \times 10^{6}$ cells per milliliter, the cells were subcultured at an initial density of $2 \times 10^{5}$ cells per milliliter into a medium containing increasing proportions of EX-CELL CHO DHFR ${ }^{-}$medium, first at 1:3 mix and then 1:7 (serum-containing medium/serum-free medium). The cells were considered adapted only when the cell density reached $1 \times 10^{6}$ cells per milliliter, with at least $90 \%$ cell viability.

\section{Gradual Adaptation to Serum-Free Medium}

First Experiment Cell line A growing in serum-containing medium was seeded in 24-well plates at a viable cell density of $2 \times 10^{5}$ cells per milliliter, in duplicate, with five different combinations of medium supplements (insulin and trace elements), as described in Table 1. Negative (cells growing in serum-containing medium without additional supplementation) and positive (cells growing in serum-containing medium with gradual reduction of serum percentage without additional supplementation) controls were also assessed. A methodology of gradual adaptation was implemented based on sequential reduction of serum percentage 
Table 1 Composition of the different combinations of medium supplements assessed in the gradual methodology of cell adaptation to serum-free medium

\begin{tabular}{|c|c|c|c|c|c|c|c|}
\hline \multirow[t]{2}{*}{ Medium supplement } & \multirow[t]{2}{*}{ Function } & \multirow[t]{2}{*}{ Concentration (M) } & \multicolumn{5}{|c|}{ Combination } \\
\hline & & & 1 & 2 & 3 & 4 & 5 \\
\hline RhInsulin & Growth factor & $3.43 \times 10^{-7}$ & $\mathrm{X}$ & $\mathrm{X}$ & $X$ & $\mathrm{X}$ & $\mathrm{X}$ \\
\hline Copper sulfate $\left(\mathrm{CuSO}_{4}\right)$ & Proliferation & $1.00 \times 10^{-8}$ & $\mathrm{X}$ & $\mathrm{X}$ & & $\mathrm{X}$ & $\mathrm{X}$ \\
\hline Zinc sulfate $\left(\mathrm{ZnSO}_{4}\right)$ & Proliferation & $5.33 \times 10^{-6}$ & $\mathrm{X}$ & $\mathrm{X}$ & & $\mathrm{X}$ & $\mathrm{X}$ \\
\hline Sodium selenite $\left(\mathrm{Na}_{2} \mathrm{SeO}_{3}\right)$ & Antioxidant & $1.00 \times 10^{-7}$ & $\mathrm{X}$ & $\mathrm{X}$ & & $\mathrm{X}$ & $\mathrm{X}$ \\
\hline Ammonium iron citrate $\left(\mathrm{FeC}_{6} \mathrm{H}_{5} \mathrm{O}_{7} \cdot \mathrm{NH}_{4} \mathrm{OH}\right)$ & Proliferation & $3.57 \times 10^{-4}$ & $\mathrm{X}$ & & & $\mathrm{X}$ & \\
\hline Ferrous ammonium sulfate $\left(\mathrm{NH}_{4} \mathrm{Fe}\left(\mathrm{SO}_{4}\right)_{2}\right)$ & Proliferation & $3.76 \times 10^{-4}$ & & $\mathrm{X}$ & & & $\mathrm{X}$ \\
\hline Ammonium metavanadate $\left(\mathrm{NH}_{4} \mathrm{VO}_{3}\right)$ & Unknown & $5.47 \times 10^{-9}$ & & & $\mathrm{X}$ & $\mathrm{X}$ & $\mathrm{X}$ \\
\hline Nickel chloride $\left(\mathrm{NiCl}_{2}\right)$ & Unknown & $1.00 \times 10^{-9}$ & & & $\mathrm{X}$ & $\mathrm{X}$ & $\mathrm{X}$ \\
\hline Stannous chloride $\left(\mathrm{SnCl}_{2}\right)$ & Unknown & $6.33 \times 10^{-10}$ & & & $\mathrm{X}$ & $\mathrm{X}$ & $\mathrm{X}$ \\
\hline
\end{tabular}

by half at each step, after assuring successful cell adaptation from the previous step. When the cultures reached $0.625 \%$ of serum, the medium composition was gradually switched to the chemically defined serum-free EX-CELL CHO DHFR ${ }^{-}$medium. It should be noted that cells were subcultured in six-well plates and later in $25-\mathrm{cm}^{2}$ flasks when they had reached $90 \%$ confluence. At every passage step of the process, samples were taken for analysis of cell productivity. Cell concentration and viability were assessed by trypan blue exclusion.

Second Experiment Problems were detected during the first experiment leading to the development of an improved methodology of cell adaptation with the following modifications: cells were cultured in $25-\mathrm{cm}^{2}$ flasks with a higher initial cell concentration $\left(4 \times 10^{5}\right.$ cells per milliliter); cell lines $\mathrm{B}$ and $\mathrm{C}$ were also used to assess the possible impact of transfection on the process of adaptation; only combinations $\mathrm{C} 2, \mathrm{C} 3$, and $\mathrm{C} 5$ (Table 1) were tested; procedures that were harsh to the cells, such as those involved with subculture (centrifugation and the use of enzymes) were avoided; and the time given to the cells to adapt at each step of the process was increased.

Since subculture procedures were being avoided, a quantitative analysis of cell concentration was not possible during the first steps of the process when cells were growing adherently. Therefore, to allow a qualitative assessment of this parameter, micrographs were taken during these steps. After the cells started to detach and grow in suspension, cell concentration and viability were assessed by the usual trypan blue exclusion method.

Cryopreservation and Thawing of Serum-Free Cells

At different steps of the process of cell adaptation to serum-free medium cells were cryopreserved. Initially, this was done using the routine procedure, preserving cells in DMEM supplemented with the corresponding percentage of serum and $5 \%$ dimethyl sulfoxide (DMSO, Frilabo, Maia, Portugal) and using the Mr. Frosty system (SigmaAldrich) to provide a freezing rate of approximately $-1{ }^{\circ} \mathrm{C} / \mathrm{min}$. As some problems were found during the recovery of the frozen cells, an optimization of the cryopreservation and thawing procedures was attempted. More rigorous and delicate procedures were applied, consisting of preserving cells in $40 \%$ conditioned medium (medium in which cells were 
growing), $55 \%$ DMEM or EX-CELL supplemented with the corresponding serum percentage, and $5 \%$ DMSO, by adding this medium to the cells in a dropwise manner. To thaw cells, they were warmed at $37^{\circ} \mathrm{C}$ until only an ice crystal remained, the growth medium was added dropwise, the cells were centrifuged (180 g, $5 \mathrm{~min}$ ), and fresh growth medium was once again added dropwise.

\section{Antibody Quantification}

Samples were analyzed for antibody productivity by enzyme-linked immunosorbent assay (ELISA) following a confidential procedure described in SOP 2008-01 ANL from Biotecnol SA, Portugal. Briefly, plates were coated with capture antibody overnight and blocked for 45 min at room temperature. Dilutions of the samples were added, as well as a standard of known concentration and a quality control, and the plates incubated for $2 \mathrm{~h}$ at $37{ }^{\circ} \mathrm{C}$. The detection antibody was added and the plates incubated for $2 \mathrm{~h}$ at room temperature, after which, a 3,3',5,5'-Tetramethylbenzidine (TMB, Sigma-Aldrich) substrate solution was added and allowed to react for $10 \mathrm{~min}$ at room temperature. After stopping the reaction, absorbance was read at $450 \mathrm{~nm}$.

\section{Statistical Analysis}

Statistical analysis was performed using SPSS software (Statistical Package for the Social Sciences). MAb production data were assessed using one-way analysis of variance with Bonferroni's test and a confidence level of $95 \%$.

\section{Results and Discussion}

Evaluation of the Cell Adaptation Methodology

\section{First Experiment}

In this work, a first attempt to adapt cell line A (CHO-K1 cell line transfected with CAB051 $\mathrm{mAb}$ by $\mathrm{OSCAR}^{\mathrm{TM}}$ technology) to serum-free conditions was made. The timeline of the process of adaptation used and the main observations are shown in Fig. 1. In this first experiment, the percentage of serum was reduced to no more than $0.31 \%$, level at which cells died after 45 days of culture. These less positive results were related to different factors. The first consisted of the use of a low initial cell concentration $\left(2 \times 10^{5}\right.$ cells per milliliter $)$ in small culture surfaces (24-well plates). In fact, with a procedure so demanding to the cells, the use of higher initial cell concentration and higher culture surface may result in a higher number of surviving cells, increasing the probability of successful adaptation. Furthermore, the use of 24and 6-well plates poses an extra problem for cell concentration monitoring since cells tend to concentrate in the middle of the well, leading to irregular sampling and deceptive results.

Second, since cells are much more sensitive during this demanding process of adaptation, the use of common procedures in cell culture, like centrifugation and the use of enzymes (e.g. trypsin) can be damaging. This deleterious effect was observed when cells were subcultured into new culture flasks and in some steps of serum reduction. In these steps, a decrease in cell viability and changes of morphology, with cells becoming smaller and irregular, were observed. Therefore, it is concluded that such harsh culture procedures should be avoided whenever possible. 


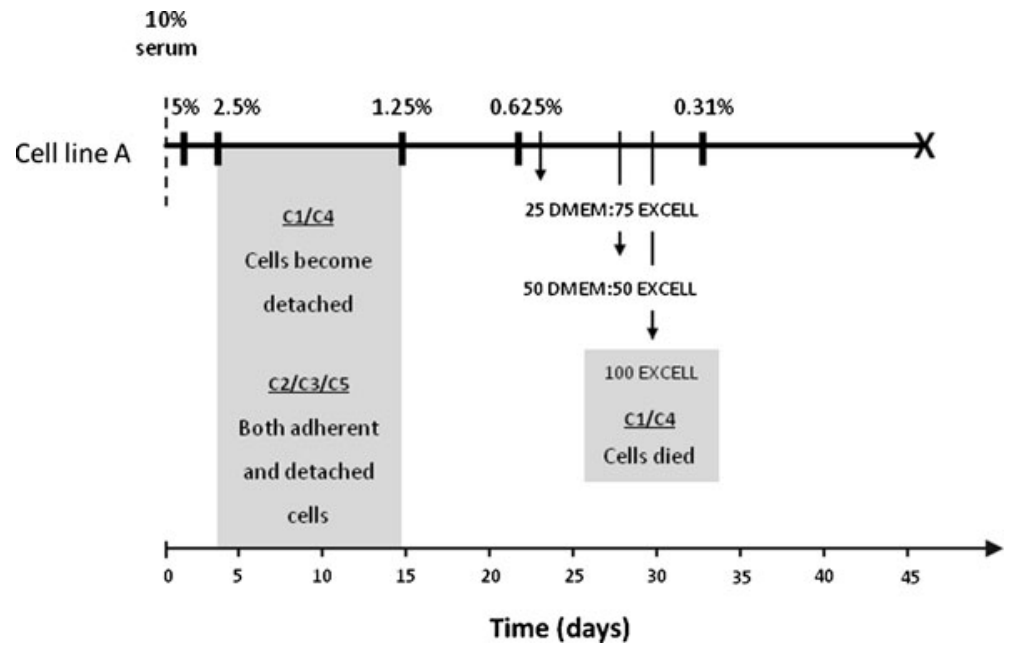

Fig. 1 Timeline of the first attempt to adapt cell line A to serum-free medium, starting with a supplementation of $10 \%$ of serum. All the combinations of medium supplements (C1-C5) were used

Third, the continuous reduction of cell concentration during the process of adaptation may also be a consequence of insufficient time given to a full adaptation of cells at each step of the process. Indeed, time is probably the most important factor for the success of serumfree adaptation, and cells should be given enough time to acquire a healthy appearance and an obvious growth at each stage of serum reduction.

Concerning the different combinations of trace elements tested, it was observed that $\mathrm{C} 1$ and $\mathrm{C} 4$ had the worst effects on cell adaptation. With these combinations, cells became fully detached with low viabilities very early in the process $(2.5 \%$ serum $)$ and ended up dying at $0.625 \%$ serum (day 29). This was most likely caused by the presence of the trace element ammonium iron citrate, common to both combinations and not present in $\mathrm{C} 2, \mathrm{C} 3$, and $\mathrm{C} 5$, which all gave similar and slightly better results than $\mathrm{C} 1$ and $\mathrm{C} 4$, reaching $0.31 \%$ serum (the composition and effect of the different combinations of supplements will be discussed later on). In consequence of the results obtained for combinations $\mathrm{C} 1$ and $\mathrm{C} 4$, these were not used in the second set of experiments.

\section{Second Experiment}

After identifying the problems of the first adaptation procedure, corrective measures were implemented in a second attempt. The results of this second experiment on serum-free adaptation are represented as a timeline in Fig. 2. Comparing the results presented in Fig. 2 with those of Fig. 1, the most notable change is the time of adaptation given at each step of the process, which was greatly increased in this second procedure. At each level of serum, full adaptation was assured by the observation of good cell proliferation and viability.

Concerning cell line A, Fig. 2 shows that approximately 280 days were needed to reach serum-free conditions. In this time course, only 20 days were needed to reach cell adaptation to $1.25 \%$ serum, without notice of significant changes in cell behavior (growth and morphology). Likewise, the adaptation from growth in DMEM medium to growth in the chemically defined EX-CELL medium with $0.625 \%$ serum was straightforward and achieved in just 10 days. From this point on, with cells growing in EX-CELL, the process 


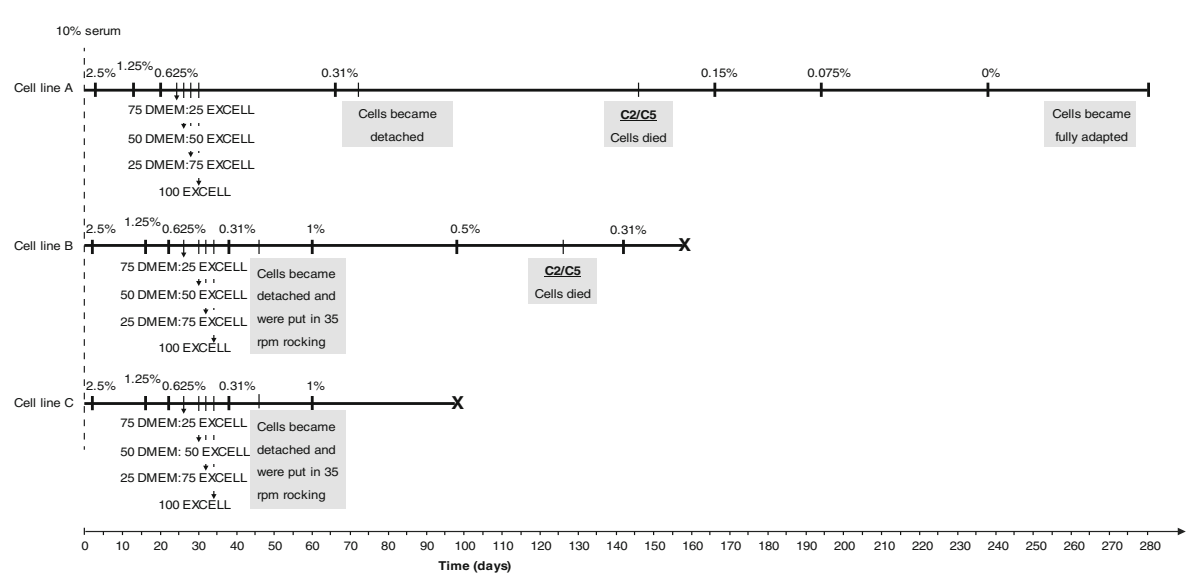

Fig. 2 Timeline of the second attempt to adapt cell line A to serum-free medium, starting with a supplementation of $10 \%$ serum. Cell lines B and $\mathrm{C}$ were also subjected to the process of adaptation. Only combinations of medium supplements $\mathrm{C} 2, \mathrm{C} 3$, and $\mathrm{C} 5$ were used

became more time consuming, demanding a greater effort from the cells to adapt. As can be seen in Fig. 2, the most critical step was $0.31 \%$ serum, the level at which the cells started to become detached and to grow in suspension. With this change in their behavior, it became possible to expand the cultures to new flasks without resorting to the aggressive procedures of trypsinization and/or centrifugation. Indeed, up to this point, cells were maintained in the same culture flasks exactly to avoid these procedures identified as one of the reasons for the failure of the first attempt of adaptation. However, this prevented the quantification of cell density up to the point where cells started to grow detached (during the $0.31 \%$ stage); therefore, the progress of this parameter was documented by taking micrographs, as shown in Fig. 3. In this figure, it is possible to observe that at $0.31 \%$ serum, cells growing in medium supplemented with $\mathrm{C} 2$ and $\mathrm{C} 5$ began to demonstrate increasing difficulties achieving healthy proliferation. Indeed, these combinations of supplements caused a deterioration of cell concentration, viability, and morphology over time, culminating in their death at day 146. It should be noted that the same behavior was observed for the control of cells growing in medium without supplementation. In opposition, cells growing in medium supplemented with C3 were able to fully adapt to this level of serum and progress in the adaptation procedure. These results indicate that the composition and concentration of the combinations used to supplement the growth medium clearly influence the ability of the cells to adapt to serum-free conditions, which is in accordance with previous studies [11-13]. The selection of the trace elements and respective combinations assessed in this study was based on the composition of commercially available solutions of these compounds, on the composition of basal culture media and serum, and on studies concerning the enhancement of medium performance using trace elements $[13,15]$. Specifically, the elements copper, zinc, selenite, and iron were selected due to their often reported importance in medium optimization, with iron, cooper, and zinc playing a role in different mechanisms that ultimately affect cell growth, differentiation, development, and maintenance, and selenite acting as an antioxidant [13]. The effects of the remaining traces used in this study (Table 1) are not yet understood in in vitro cell culture, but these compounds have been associated to several important functions in vivo, such as the metabolism of folate 

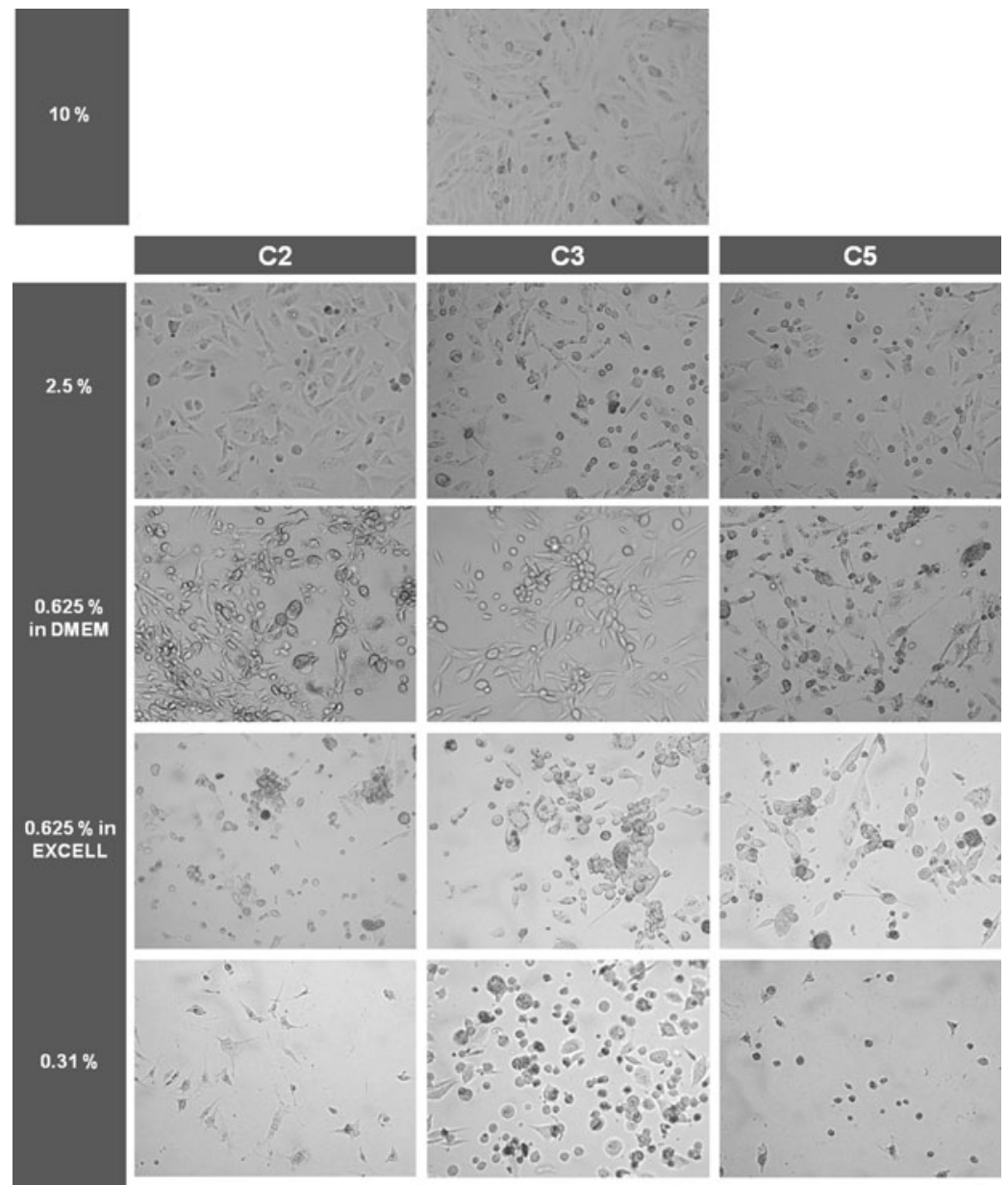

$0.15 \%$
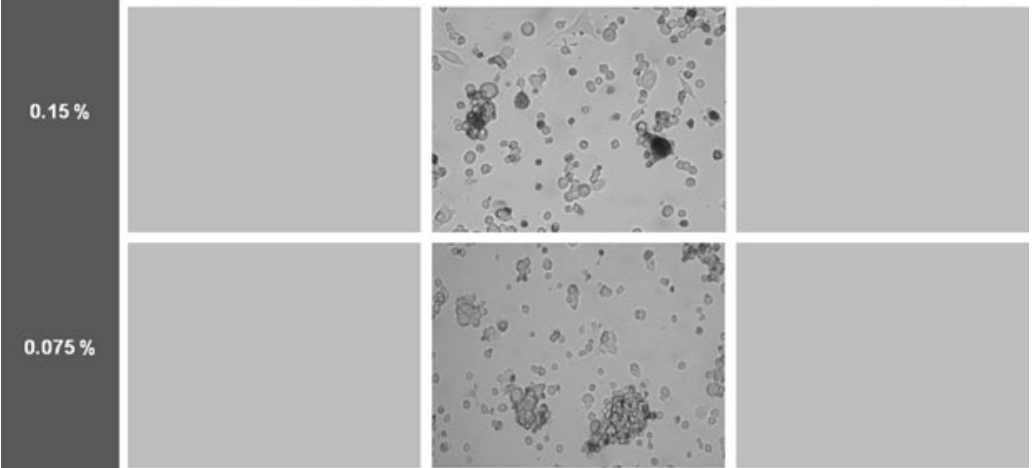

$0.075 \%$
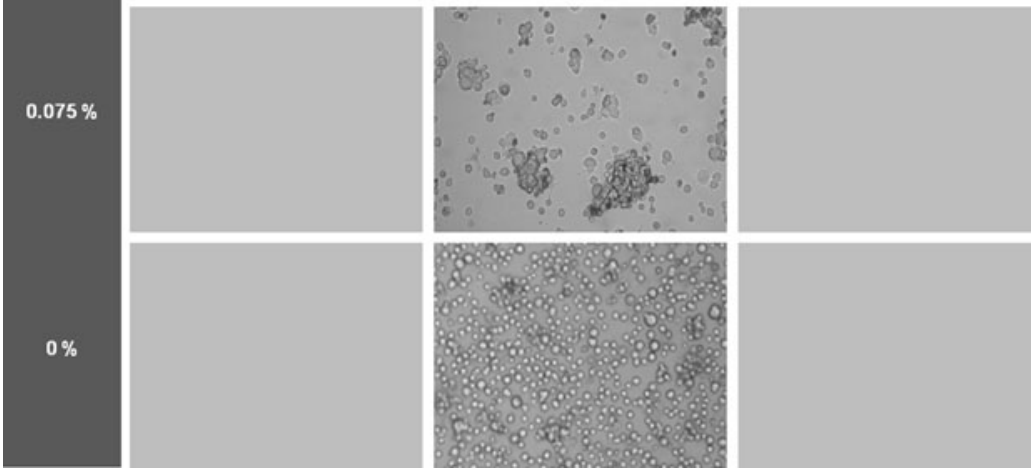
Fig. 3 Microscopic images ( $\times 200$ magnification) of cell line A cells growing at different stages of serum supplementation during the process of adaptation to serum-free medium, using combinations of trace elements $\mathrm{C} 2, \mathrm{C} 3$, and $\mathrm{C} 5$

(nickel), support of the immune system (stannous), and maintenance of a healthy blood sugar/insulin levels (metavanadate) [15]. Although the exact functions may not be known, the trace compounds and their combinations can be advantageous in serum-free or even chemically defined media. Indeed, it was interesting to note that in the present study, the combination C3, containing the least researched trace elements, was in fact the most advantageous and the only enabling a complete adaptation of cell line A to serum-free medium. The more extensively researched elements of copper, zinc, selenite, and iron, present in the remaining combinations, seemed to be detrimental for cell line A since even in combination $\mathrm{C} 5$, where the elements of $\mathrm{C} 3$ are also present, cells were unable to adapt. A possible explanation for these results is that the influence of the trace elements in the culture is not simply additive, and according to the combinations and concentrations of elements used, synergistic or antagonistic effects can be obtained. Therefore, the most known elements used in combinations $\mathrm{C} 1, \mathrm{C} 2, \mathrm{C} 4$ and $\mathrm{C} 5$ could have had antagonistic effects in the cells assessed, resulting in a negative influence on cell growth and adaptation. One potential reason for these results is related to the presence of iron in all the combinations with negative results. Iron is a critical component in cell culture, being essential for a healthy cell growth. The uptake of iron by the cells is complex and usually mediated and controlled by transferrin, which is present in the serum supplemented to the culture medium $[4,6,16]$. However, in serum-free conditions, transferrin is absent, and iron becomes even more critical, being common to supplement the culture with additional quantities of this element to ensure its delivery to the cells [7]. This was the main reason for using concentrations of iron higher than those of the remaining trace elements used in this study (Table 1). However, the supplementation of iron without the presence of transferrin to bind this element and control its delivery to the cells may lead to oxidative reactions that can damage the cells (oxidative stress) or result in uncontrolled uptake of iron by the cells $[9,16]$. It is possible that this effect occurred in the present study since the differences between the combinations containing iron and $\mathrm{C} 3$ only become detectable at lower levels of serum percentage, where the levels of transferrin may have become too low to mediate iron delivery to the cells and therefore, impair cell growth.

After adapting to the stage of $0.31 \%$ serum, cells showed a tendency to maintain high levels of viability that resulted in easier and faster adaptation to the remaining stages of the process. Furthermore, at the end of the $0.075 \%$ serum and especially during the $0 \%$ serum stages, cell proliferation was visibly improved (Fig. 3), making it easier to expand the culture and create a cell bank.

In this second experiment, two additional cell lines were also assessed: cell line B (CHO$\mathrm{K} 1$ cell line ATCC CCL-61) and cell line C (CHO-K1 cell line producing CAB051 mAb, transfected by a common technology). These cell lines had a similar behavior to cell line A at the highest serum concentrations. However, at $0.31 \%$ serum, with cells becoming detached and growing in suspension, a decision was made to place the cells in rocking conditions $(35 \mathrm{rpm})$ in an attempt to promote their growth in suspension. After a short time cultured in these conditions, the viability of cells started to decrease, and their morphology changed to smaller and irregular cells. Therefore, agitation was removed and cells were supplemented with an increased percentage of serum (1\%) in an attempt of recovery. With cell line C, recovery was not possible, and cells died at day 98. As for cell line B, it was possible to recover some cells and to proceed with the adaptation process but only down to $0.31 \%$ serum, stage at which cells died (day 156). It should be mentioned that with 
combinations $\mathrm{C} 2$ and $\mathrm{C} 5$, the cultures died earlier (day 126), indicating that $\mathrm{C} 3$ is also the best combination for the adaptation of cell line B.

Due to the negative consequences of adding rocking to the cultures of both cell line B and cell line $\mathrm{C}$, this procedure was not applied to the adaptation process of cell line A.

The different behaviors of the three CHO-K1 cell lines assessed in this study indicate that the process of adaptation is highly cell line dependent. This constitutes a major impediment for the definition of a general protocol for serum-free adaptation.

At each step of the process of cell adaptation to serum-free conditions, cells were cryopreserved. When performing the thawing of these cells, it was found that they had low viabilities (around $50 \%$ ) and took too long to recover. This was attributed to the high sensitivity of the adapted cells, which makes them more vulnerable to centrifugation, the presence of the toxic DMSO, as well as to the abrupt temperature and osmotic changes involved in the cryopreservation and thawing procedures. As a consequence, it was necessary to optimize both procedures, to make them more reproducible and delicate to the cells. It was found that the use of conditioned medium in the freezing medium was favorable, presumably due to the presence of metabolic products of cell growth that confer extra protection to the cells. Furthermore, adding the DMSO-containing freezing medium to the cells in a dropwise manner was also beneficial.

Regarding the process of thawing, cells should be allowed to warm rapidly at $37{ }^{\circ} \mathrm{C}$ just until an ice crystal remains, and fresh growth medium should be added to the cells in a dropwise manner in order to reduce osmotic shock/stress. At this point, there are two factors of stress to the cells that need to be taken into consideration: centrifugation and the presence of the toxic DMSO. Cells can either be centrifuged to remove the DMSO-containing medium, which removes the toxicity of this product but introduces extra stress (mechanical) to the cells or they can be left to grow in the DMSO-containing medium. Both procedures were evaluated, and it was found that cells support the mechanical stress of centrifugation better than the toxicity of DMSO, particularly at the lowest percentages of serum, where cells are growing in suspension and it is not possible to completely renew the medium. After centrifugation, new growth medium should also be added to the cells dropwise. By implementing these changes in the procedures of cryopreservation and thawing, the percentage of cell recovery was raised from 50 to $90 \%$.

\section{Effects of Medium Adaptation on Monoclonal Antibody Production}

The different steps of the process of cell adaptation to growth in serum-free conditions may have an important impact on their ability to produce mAbs. To evaluate this, samples were taken from the cultures at different stages of serum supplementation, and the mAb produced was quantified by ELISA. The results obtained are shown in Fig. 4. It is notable that a significant $(p<0.05)$ increase of mAb production, of about one order of magnitude, occurred for combination $\mathrm{C} 3$ from 0.625 to $0.31 \%$ of serum. It was at this point that cells were switched from growth in DMEM culture medium to the chemically defined EX-CELL medium. Cell density during this switch remained similar (Fig. 3), so the most probable cause for the increase of mAb production observed is the use of EX-CELL, whose composition is specifically prepared to compensate for the absence of serum and to promote the productivity of $\mathrm{CHO}$ cells. In the previous analysis of Fig. 2, it was observed that the time required for cells to adapt to each level of serum becomes longer at $0.31 \%$, when cells start growing in EX-CELL. It is possible that a metabolic shift occurs at this stage, with the main focus of cells changing from proliferation to $\mathrm{mAb}$ production. Indeed, this inverse relationship between cell growth and production has been often discussed as an approach to 


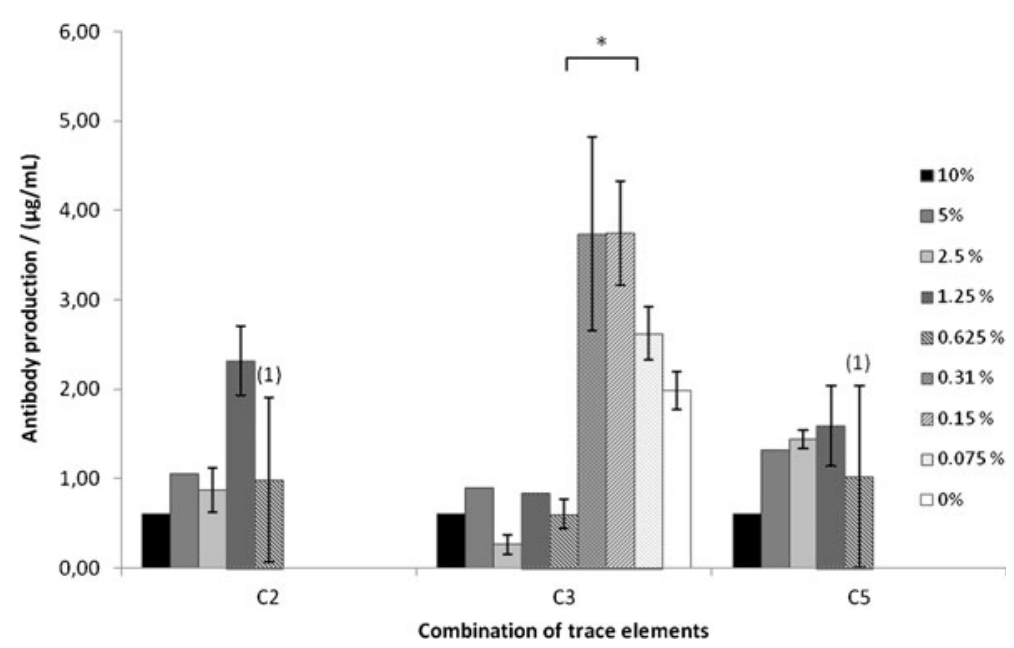

Fig. 4 Evolution of monoclonal antibody production by CHO-K1 cells (cell line A) through the different levels of serum percentage of the process of adaptation. Production is shown for cells growing in the three combinations of medium supplements tested (C2, C3, and C5). (1) The high standard deviations are a consequence of the abrupt $\mathrm{mAb}$ production decrease associated with cell death at this level of serum. Single asterisk (*) represents statistical differences $(p<0.05)$ between serum concentrations

optimize production processes. Examples of such strategies include the use of culture temperatures lower than the ideal for cell growth [1, 28], small changes in $\mathrm{pH}[14]$, and hyperosmolarity [20]. Further reduction of serum percentage to $0.075 \%$ and $0 \%$ led to a decrease in $\mathrm{mAb}$ production to levels that although still higher than the initial values, were no longer significantly different. It was also at these levels of serum that cell density became similar to that of the initial conditions (10\% serum), which may have caused a decrease of $\mathrm{mAb}$ production by reducing the specific productivity of the cells, in an effect inverse to that observed after the shift to EX-CELL.

Concerning combinations $\mathrm{C} 2$ and $\mathrm{C} 5$, there were no significant changes in mAb production during the process of adaptation. However, these cells were only able to grow until $0.625 \%$ serum, after which a total decay of cell proliferation occurred, culminating in their death and an abrupt decrease of $\mathrm{mAb}$ production (hence, the high standard deviations observed). Since the change of culture medium to EX-CELL at $0.625 \%$ probably causes a shift in the metabolic behavior of cells, it is possible that cells growing in combinations $\mathrm{C} 2$ and C5 were not capable of supporting such adjustment.

Comparing the three combinations of medium supplements used, no significant differences were generally detected in the levels of production at each stage of serum. However, two exceptions were noted $(p<0.05)$, namely for all combinations at $2.5 \%$ serum and between $\mathrm{C} 2$ and $\mathrm{C} 3$ at $1.25 \%$ serum. In these cases, it is curious to note that $\mathrm{C} 3$ is the combination achieving the lower levels of production.

\section{Conclusion}

The adaptation of mammalian cells to growth in serum-free conditions is still one of the most challenging and time-consuming processes of cell culture. In this work, some basic guidelines were established to support the development of procedures for the adaptation of 
different cells lines to growth in serum-free conditions. These guidelines identify the most potentially damaging procedures of the process, such as centrifugation, trypsinization, and cryopreservation, and highlight the importance of the selection of medium supplements (e.g. trace elements) to use during cell adaptation. Indeed, among the five supplement combinations assessed in this study, only the combination of ammonium metavanadate, nickel chloride and stannous chloride (C3) resulted in the successful adaptation of CHO-K1 cells to serum-free medium. However, it must be highlighted that the amount of time given at each step of the process, as well as the cell type, are determinant factors for the success of the process of adaptation, and therefore the support protocol here defined should be adapted to the particular requirements of each cell line.

The process of adaptation also affected the levels of mAb production, in two ways: the shift of medium from DMEM to the chemically defined EX-CELL benefited mAb production and the complete removal of serum from the culture reduced these positive effects but still resulted in levels of production slightly superior to those of the initial serum-supplemented conditions.

Acknowledgments The authors acknowledge funding and support from the Portuguese Foundation for Science and Technology (FCT), namely grant ref SFRH/BD/46661/2008 for Maria Elisa Rodrigues and SFRH/BD/46660/2008 for Ana Rita Costa.

\section{References}

1. Bollati-Fogolín, M., Forno, G., Nimtz, M., Conradt, H. S., Etcheverrigaray, M., \& Kratje, R. (2005). Biotechnology Progress, 21, 17-21.

2. Brunner, D., Frank, J., Appl, H., Schöffl, H., Pfaller, W., \& Gstraunthaler, G. (2010). ALTEX, 27, 53-62.

3. Chen, Z., Iding, K., Lütkemeyer, D., \& Lehmann, J. (2000). Biotechnology Letters, 22, 837-841.

4. Conrad, M., Umbreit, J., \& Moore, E. (1999). The American Journal of the Medical Sciences, 318, $213-$ 229

5. Doyle, A., \& Griffiths, J. B. (1998). Cell and tissue culture: laboratory procedures in biotechnology. Chichester, England: John Wiley \& Sons.

6. Elliott, R. L., Elliott, M. C., Wang, F. E. N., \& Head, J. F. (1993). Annals of the New York Academy of Sciences, 698, 159-166.

7. Eto, N., Yamada, K., Shito, T., Shirahata, S., \& Murakami, H. (1991). Agricultural and Biological Chemistry, 55, 863-865.

8. Freshney, R. I. (2005). Culture of animal cells: a manual of basic technique (5th ed.). NJ: John Wiley \& Sons.

9. García-Alfonso, C., López-Barea, J., Sanz, P., Repetto, G., \& Repetto, M. (1996). Archives of Environmental Contamination and Toxicology, 30, 431-436.

10. Griffiths, J. B. (1987). Developments in Biological Standardization, 66, 155-160.

11. Ho, E., \& Ames, B. N. (2002). Proc Nat Acad Sci, 99, 16770-16775.

12. Hutchings, S. E., \& Sato, G. H. (1978). Proc Nat Acad Sci, 75, 901-904.

13. Jacobia, S., Kenerson, R., Tescione, L., Gruber, D., Jayme, D., Munroe, D., \& Gorfien, S. (2006). Animal cell technology: basic \& applied aspects. Netherlands: Springer.

14. Jardon, M., \& Garnier, A. (2003). Biotechnology Progress, 19, 202-208.

15. Kenerson, R. W. (2005) United States Patent Application Publication, Invitrogen Corporation, US, WO/ 2006/004728.

16. Kováŕ, J., \& Franěk, F. (1989). Experimental Cell Research, 182, 358-369.

17. Lee, J., Tscheliessnig, A., Chen, A., Lee, Y. Y., Adduci, G., Choo, A., \& Jungbauer, A. (2009). Journal of Chromatography. A, 1216, 2683-2688.

18. LeFloch, F., Tessier, B., Chenuet, S., Guillaume, J.-M., Cans, P., Goergen, J.-L., \& Marc, A. (2006). Cytotechnology, 52, 39-53.

19. Liu, C.-H., \& Chang, T.-Y. (2006). Proc Biochem, 41, 2314-2319.

20. Min Lee, G., Koo, J. and Flickinger, M. C. (2009), in Encyclopedia of Industrial Biotechnology, John Wiley \& Sons. 
21. Ozturk, S., Kasebo, G., Mahaworasilpa, T., \& Coster, H. G. (2003). Hybridoma and Hybridomics, 22, $267-272$

22. Ozturk, S. S., \& Hu, W.-S. (2006). Cell culture technology for pharmaceutical and cell-based therapies. NY: CRC Press.

23. Ozturk, S. S., \& Palsson, B. O. (1991). Biotechnology and Bioengineering, 37, 35-46.

24. Rodrigues, M. E., Costa, A. R., Henriques, M., Azeredo, J., \& Oliveira, R. (2009). Biotechnology Progress, 26, 332-351.

25. Schröder, M., Matischak, K., \& Friedl, P. (2004). Journal of Biotechnology, 108, 279-292.

26. Sinacore, M., Drapeau, D., \& Adamson, S. (2000). Molecular Biotechnology, 15, 249-257.

27. Sung, Y. H., Lim, S. W., Chung, J. Y., \& Lee, G. M. (2004). Applied Microbiology and Biotechnology, 63, $527-536$.

28. Trummer, E., Fauland, K., Seidinger, S., Schriebl, K., Lattenmayer, C., Kunert, R., Vorauer-Uhl, K., Weik, R., Borth, N., Katinger, H., \& Müller, D. (2006). Biotechnology and Bioengineering, 94, 10331044.

29. Tsao, Y.-S., Condon, R., Schaefer, E., Lio, P., \& Liu, Z. (2001). Cytotechnology, 37, 189-198.

30. Werner, R. G., Noe, W., Kopp, K., \& Schlüter, M. (1998). Arzneimittel Forschung, 48, 870-880.

31. Wong, V., Wong, N., Tan, H.-K., Wang, D. and Yap, M. (2003) Mol. Eng. Biol. Chem. Sys. (MEBCS).

32. Wurm, F. M. (2004). Nat Biotech, 22, 1393-1398.

33. Zhang, J., \& Robinson, D. (2005). Cytotechnology, 48, 59-74. 